\title{
Hyperthermic intraperitoneal chemotherapy in prevention of gastric cancer metachronous peritoneal metastases: a systematic review
}

\author{
Mikhail Yu. Reutovich ${ }^{1}$, Olga V. Krasko ${ }^{2}$, Oleg G. Sukonko ${ }^{1}$ \\ ${ }^{1}$ Gastroesophageal Pathology Department, N.N. Alexandrov National Cancer Center, Minsk, Belarus; ${ }^{2}$ United Institute of Informatics Problems, \\ National Academy of Sciences, Minsk, Belarus \\ Contributions: (I) Conception and design: MY Reutovich, OV Krasko; (II) Administrative support: None; (III) Provision of study materials or patients: \\ MY Reutovich, OV Krasko; (IV) Collection and assembly of data: MY Reutovich; (V) Data analysis and interpretation: MY Reutovich, OV Krasko; (VI) \\ Manuscript writing: All authors; (VII) Final approval of manuscript: All authors. \\ Correspondence to: Mikhail Yu. Reutovich. N.N. Alexandrov National Cancer Center, Minsk, Belarus. Email: mihail_revtovich@yahoo.com.
}

\begin{abstract}
Gastric cancer progression resulting in metachronous peritoneal metastasizing is almost always associated with an adverse prognosis. This review discusses various options of preventing metachronous peritoneal metastases in radically operated gastric cancer patients. Also examined are different hyperthermic intraperitoneal chemotherapy (HIPEC) regimens employed in gastric cancer treatment, postoperative morbidity and mortality rates and long-term treatment outcomes. The authors also review their own experience of using HIPEC based on the combination of cisplatin and doxorubicin in doses of $50 \mathrm{mg} / \mathrm{m}^{2}$ at $42 \mathrm{C}$ for $1 \mathrm{~h}$ to prevent gastric cancer peritoneal dissemination. As a result, progression-free survival rose from $19.6 \% \pm 5.6 \%$ to $47.1 \% \pm 6.3 \%\left(\mathrm{P}_{\log -\text { rank }}<0.001\right)$ and dissemination-free survival-from $22.7 \% \pm 6.0 \%$ to $51.9 \% \pm 6.3 \%\left(\mathrm{P}_{\log \text {-rank }}<0.001\right)$. It is noted that the combination of the described HIPEC regimen with systemic chemotherapy helped raise metastases-free 3 -year survival rate to up to $91.0 \% \pm 9.0 \%\left(\mathrm{P}_{\text {log-rank }}=0.025\right)$ compared with $48.6 \% \pm 6.4 \%$ for patients who underwent only a combined surgery/HIPEC treatment. HIPEC is a promising combined treatment strategy for radically operated gastric cancer patients that can improve patient survival and decrease peritoneal dissemination rate. However, the number of randomized studies on adjuvant HIPEC are still insufficient for a subgroup assessment of efficacy of the given chemotherapy regimens and generation of evidence-based recommendations on the individual use of chemotherapy agents and their combinations, and HIPEC procedural techniques. Further prospective randomized studies are needed to assess the practicability of complementing HIPEC with adjuvant systemic chemotherapies.
\end{abstract}

Keywords: Gastric cancer (GC); hyperthermic intraperitoneal chemotherapy (HIPEC); early postoperative intraperitoneal chemotherapy (EPIC); extensive intraperitoneal lavage (EIPL)

Submitted Feb 26, 2020. Accepted for publication Jun 29, 2020.

doi: 10.21037/jgo-20-129

View this article at: http://dx.doi.org/10.21037/jgo-20-129

\section{Topicality}

Metachronous peritoneal metastases (MPM) are the most common and earliest form of gastric cancer (GC) progression despite performing radical surgery (1). They are observed to occur in nearly $50 \%$ of radically operated patients (2) and are associated with an extremely unfavorable prognosis. For example, according to the population-based study undertaken in the Netherlands in 2014 the median overall survival (OS) rate for patients with peritoneal metastases alone was 4.6 and 3.3 months for patients with peritoneal metastases aggravated by the presence of other distant metastases (3). The most adverse prognostic factors of disease progression are serosal 
tumor invasion and regional lymph node metastases $(4,5)$. Exfoliation of tumor cells from the serosal surface and their dissemination from transected lymphatic vessels during lymphadenectomy, especially in the presence of regional lymph node metastases $(5,6)$, are the most frequent cause of tumor cell spread in the peritoneum. It is their appearance in the peritoneum that is perceived as the starting moment of MPM development. Regrettably, administration of adjuvant systemic chemotherapy (SCT) failed to produce any effect on MPM frequency $(7,8)$. Apparently, due to the peritoneal-plasma barrier the desired treatment outcome can only be achieved by employing locoregional therapy to block the dissemination of free cancer cells and ensure their complete eradication in the abdominal and pelvic cavity.

\section{Methods of preventing metachronous peritoneal metastatic dissemination}

According to the ClinicalTrials.gov website, there are three basic approaches that are currently employed to eliminate free cancer cells in the peritoneum after performing radical surgery, namely: (I) extensive intraperitoneal lavage (EIPL); (II) intraperitoneal chemotherapy (IPC), including HIPEC; and (III) normothermic postoperative IPC, including early postoperative intraperitoneal chemotherapy (EPIC) (1).

EIPL has proved to be a promising treatment option. Kuramoto et al. (9) showed that extensive EIPL in combination with IPC achieved a 5 -year survival of $43.8 \%$. That was a lot higher than in the patients who underwent only IPC treatment $(4.6 \%, \mathrm{P}<0.0001)$ or in the patients who underwent only surgical treatment $(0 \%, \mathrm{P}<0.0001)$. However, according to the data of a randomized phase III trial conducted to evaluate the potential of EIPL in addition to standard treatment for $\geq \mathrm{T} 3$ resectable GC (CCOG 1102) the administration of EIPL without IPC follow-up therapy showed no significant difference in the 3-year disease-free survival (DFS) for pT4a-b patients (63.9\% in the EIPL group and $59.7 \%$ in the non-EIPL group, $\mathrm{P}=0.25)$. Regarding OS, it was $75.0 \%$ and $73.7 \%$, respectively, $\mathrm{P}=0.65$ (10). For this reason, the scope of EIPL use in the prevention of peritoneal dissemination is fairly limited.

The second approach, normothermic intraoperative IPC, unlike HIPEC, has a marginal adjuvant effect according to Yan et al. (11). In their opinion, hyperthermia offers a synergistic and/or complementary anti-tumor effect in comparison to IPC. In their meta-analysis of similar studies Huang et al. (12) also came to a conclusion regarding a higher efficacy of HIPEC over normothermic intraoperative IPC.

Of the three approaches HIPEC appears to be the most widely used method of preventing postoperative GC recurrence that is for the most part represented by MPM (13). Besides its obvious mechanical washing effect, HIPEC offers the advantage of a direct cytotoxic effect of heat in addition to a high local drug concentration (14). There is increased cytotoxicity and penetration of chemotherapy agents into the peritoneal cavity tissue (15-17), a higher anticancer drug concentration delivery into the abdominal lavage, and reduced systemic toxicity. At the molecular level, HIPEC owes its effect to induction of apoptosis, alterations in cell membrane properties, changes in intracellular proteins and their synthesis, and heat inhibition of DNA repair enhanced by inhibitors of the cellular heat-shock response $(18,19)$. In summary, the data available to date on the application of the three approaches to the prevention of MPM development testify to a higher efficacy of HIPEC versus the other two approaches as evidenced by a number of meta-analyses (11,12,20-22).

The first report on the application of HIPEC as a prophylactic treatment for peritoneal recurrence applied after GC surgery was presented by Koga et al. in 1988 (23). The authors reported on two studies. The first, a historical study, showed improvement in 3-year survival ( $74 \%$ vs. $53 \%, \mathrm{P}<0.04)$ and reduction in the frequency of peritoneal recurrence ( $36 \%$ vs. $50 \%$ ). Their second, a randomized study, demonstrated no more than a tendency towards improving 30-month survival ( $83 \%$ vs. 67\%). Their follow-up analysis accounting for free cancer cells detected in peritoneal washings (treated group-15\%, control group-23\%) also showed only a tendency towards improved 5-year survival (64\% vs. 52\%) and a reduction in the peritoneal recurrence frequency (39\% vs. 59\%) after administering HIPEC (23).

Published data on efficacy of HIPEC in randomized trials are summed up in Table 1.

However, in the opinion of Seshadri and Glehen (28) the major drawback of studies as the ones mentioned in Table 1 is that they mainly focused on pT4 and pN1-3 GC inclusion criteria and disregarded free cancer cells. Indeed, the factoring in of this criterion is essential for forming more homogeneous groups and attaining a more solid evaluation of the efficacy or inefficacy of various adjuvant HIPEC regimens. As an example, due to heterogeneity in their study groups Kim and Bae (29) reported no statistically significant survival results between the HIPEC and control groups, 
$32.7 \%$ and $21.7 \%$, respectively. However, their results became statistically significant after excluding stage IV GC patients (58.6\% and 44.4\%). A number of studies, currently under way, such as GASTRICHIP (NCT01882933), plan to account for the $\mathrm{CY}+\mathrm{P} 0$ criterion in assessing their longterm treatment outcomes.

According to the ClinicalTrials.gov website, about 12 studies are currently under way to evaluate the efficacy of adjuvant IPC with nearly 9 of them being focused on assessing the efficacy of adjuvant HIPEC (Table 2). NonHIPEC adjuvant trials are listed in Table 3.

As can be seen from these tables, there are a wide range of prophylactic HIPEC regimens including variations in the number of postoperative HIPEC cycles, their timing, combination and dosage of chemotherapy agents. Another important feature of currently conducted studies is the administration of adjuvant and/or perioperative SCT. It is notable that all earlier studies published to date, analyzed one-time application of HIPEC in its adjuvant regimen without any follow-up adjuvant SCT. This may explain why the earlier single-application HIPEC trials were less effective in improving GC treatment outcomes as is pointed up by some authors (23-25,29,30).

The key elements of the strategy of adjuvant HIPECbased treatment of resectable GC aimed at preventing MPM include:

* Surgery. Surgery is the main and essential element of resectable GC management comprising a radical operation in combination with D2 lymphadenectomy that underlies the success of overall treatment outcome $(31,32)$. However, for all its importance, surgery is unable to prevent GC progression $(1,2)$.

* HIPEC. When added to D2 gastrectomy, HIPEC plays a crucial role in preventing GC progression.

As Tables 1,2 above show, currently there is a great diversity of HIPEC regimens in terms of the choice of temperature, timing, mode of administration (open or closed techniques), number of treatment cycles, flow rate, drug selection and dosage. Interaction of these parameters, in the long run, determines HIPEC efficacy.

\section{Prophylactic HIPEC temperature}

The most frequently used temperature parameter is $40-43{ }^{\circ} \mathrm{C}$ during 30 to 90 minutes. According to Ji et al. (1), no special studies were conducted to evaluate this parameter. Going beyond this temperature range is not recommended as raising the temperature to $44^{\circ} \mathrm{C}$ or higher results in the apoptosis of normal cells (18).

\section{Prophylactic HIPEC timing}

The currently accumulated body of experience gained from performing IPC, including HIPEC, attests to a higher efficacy and practical benefits of intraoperative chemotherapy administration because of a more complete contact of chemotherapy agents with the peritoneal surface. This view is supported by comparative studies conducted by several researchers $(15,33-35)$ and also by the results of a meta-analysis performed by Feingold et al. (22) showing a difference in the impact on 5-year survival odds in favor of immediate intraoperative IPC over delayed postoperative IPC treatment.

\section{Prophylactic HIPEC mode of administration}

There is no unanimity among researchers about advantages or disadvantages of open or closed techniques of administration. Some of them find both techniques equally effective $(15,36)$, while others favor open techniques as a better option in terms of intraperitoneal distribution, chemotherapeutic absorption and enhanced tissue uptake $(37,38,39,40)$.

\section{Prophylactic HIPEC number of cycles}

From the results of the studies on the efficacy of adjuvant HIPEC conducted to date, it can be safely concluded that at a minimum one HIPEC session administered intraoperatively during $30-90$ minutes at $40-43{ }^{\circ} \mathrm{C}$ is an efficient tool against GC progression and, most importantly, against MPM. There are no data available to date to suggest otherwise. Although there are two studies on a repeated HIPEC administration with one of them still in progress [NCT02356276 (HIPEC-01)] and the other one (NCT02396498) started in April of 2014 and scheduled to be completed in December of 2016 (Table 2) none of their results have been published to date.

\section{Prophylactic HIPEC flow rate}

As of today, there are no data with regard to evaluating the impact of the flow rate on the destruction of free cancer cells. However, based on their experimental study Furman et al. (41) reported that higher flows in the swine model 
Table 1 Results of administering prophylactic HIPEC based on randomized study data

\begin{tabular}{|c|c|c|c|}
\hline Authors & Country & HIPEC regimen & 5-year survival \\
\hline Hamazoe et al. (24) (1994) & & Control group $(n=40)$ & $52.5 \%$ \\
\hline Ikeguchi et al. (25) (1995) & Japan & $\begin{array}{l}\text { HIPEC }(n=78)-80-100 \mathrm{mg} / \mathrm{m}^{2} \text { mitomycin } \mathrm{C} \text { in } 8-10 \mathrm{~L} \text { of perfusate, } 40-42{ }^{\circ} \mathrm{C} \text {, } \\
50-60 \mathrm{~min}\end{array}$ & $66 \%$ \\
\hline Fujimoto et al. (26) (1999) & & Control group $(n=70)$ & - \\
\hline \multirow[t]{2}{*}{ Yonemura et al. (27) (2001) } & Japan & $\begin{array}{l}\text { HIPEC }(n=48)-30 \mathrm{mg} \text { mitomycin } \mathrm{C}+300 \mathrm{mg} \text { CDDP in } 6-8 \mathrm{~L} \text { of perfusate, } \\
42-43^{\circ} \mathrm{C}, 60 \mathrm{~min}\end{array}$ & $61 \%$ \\
\hline & & $\begin{array}{l}\text { Intraoperative normothermic chemotherapy }(n=44)-30 \mathrm{mg} \text { mitomycin } \mathrm{C}+ \\
300 \mathrm{mg} \text { CDDP } \\
\text { in } 6-8 \mathrm{~L} \text { of perfusate, } 37^{\circ} \mathrm{C}, 60 \mathrm{~min}\end{array}$ & $43 \%$ \\
\hline
\end{tabular}

HIPEC, hyperthermic intraperitoneal chemotherapy; CDDP, cisplatin.

(more than $2.5-3.0 \mathrm{~L} / \mathrm{min}$ ) resulted in a more rapid heating of the peritoneum and greater peritoneal/ outflow temperature gradients. That finding led them to conclude that an increased flow during clinical HIPEC is instrumental in improving peritoneal heating with lower average visceral temperatures. They state that the flow rate is an important factor in achieving and maintaining goal temperatures during HIPEC.

\section{Prophylactic HIPEC chemotherapy drug selection and dosage}

Regarding the choice of chemotherapy drugs, it is usually a matter of discussion and preferences of relevant cancer centers and their HIPEC research specialists. In general, HIPEC requires chemotherapy drugs of cellcycle nonspecific type to be used synergistically with hyperthermia, while IPC conducted in early or later postoperative periods requires cell-cycle specific drugs that ensure a longer contact with the peritoneal surface (42). Therefore, according to the published data, mitomycin C- and platinum-based combinations are as widely used as are platinum- and docetaxel-based combinations $(1,43,44)$. The study published by Mi et al. catalogues 6 combinations of drugs that have been effective in the prophylactic administration of HIPEC, namely: 5-fluorouracil, mitomycin C, cisplatin, cisplatin and 5-fluorouracil, cisplatin and mitomycin C, mitomycin C and 5-fluorouracil (21).

\section{Personal experience with a randomized trial of prophylactic HIPEC}

Given the fact that the bulk of HIPEC studies were conducted in Eastern Pacific countries, these authors decided to assess the efficacy of adjuvant HIPEC in a prospective randomized study in Belarus. The study included Borrmann type III-IV GC patients from across Belarus and was carried out in 2008-2016 at the N.N. Alexandrov National Cancer Center of Belarus (2). The patients were randomly included in the HIPEC and surgery/control groups. None of the patients in this study were administered adjuvant treatment other than HIPEC. HIPEC was administered for $1 \mathrm{~h}$ with an automatic HIPEC device. Perfusate used was Ringer's solution (5-6 L) mixed with cisplatin $50 \mathrm{mg} / \mathrm{m}^{2}$ plus doxorubicin $50 \mathrm{mg} / \mathrm{m}^{2}$ warmed to an inflow temperature of $42{ }^{\circ} \mathrm{C}$. The choice of the cisplatin/doxorubicin combination was prompted by the following considerations: (I) both agents possess a high penetrating ability that is further strengthened owing to hyperthermia $(42,45)$; (II) cisplatin is one of the most effective cytostatic agents widely used in GC management $(21,22,33,39,42,46)$; and (III) doxorubicin, acting in synergy with cisplatin, is effective in suppressing gastric adenocarcinoma growth by inducing subperitoneal 
Table 2 Ongoing clinical trials of HIPEC in the prophylaxis of GC peritoneal metastases

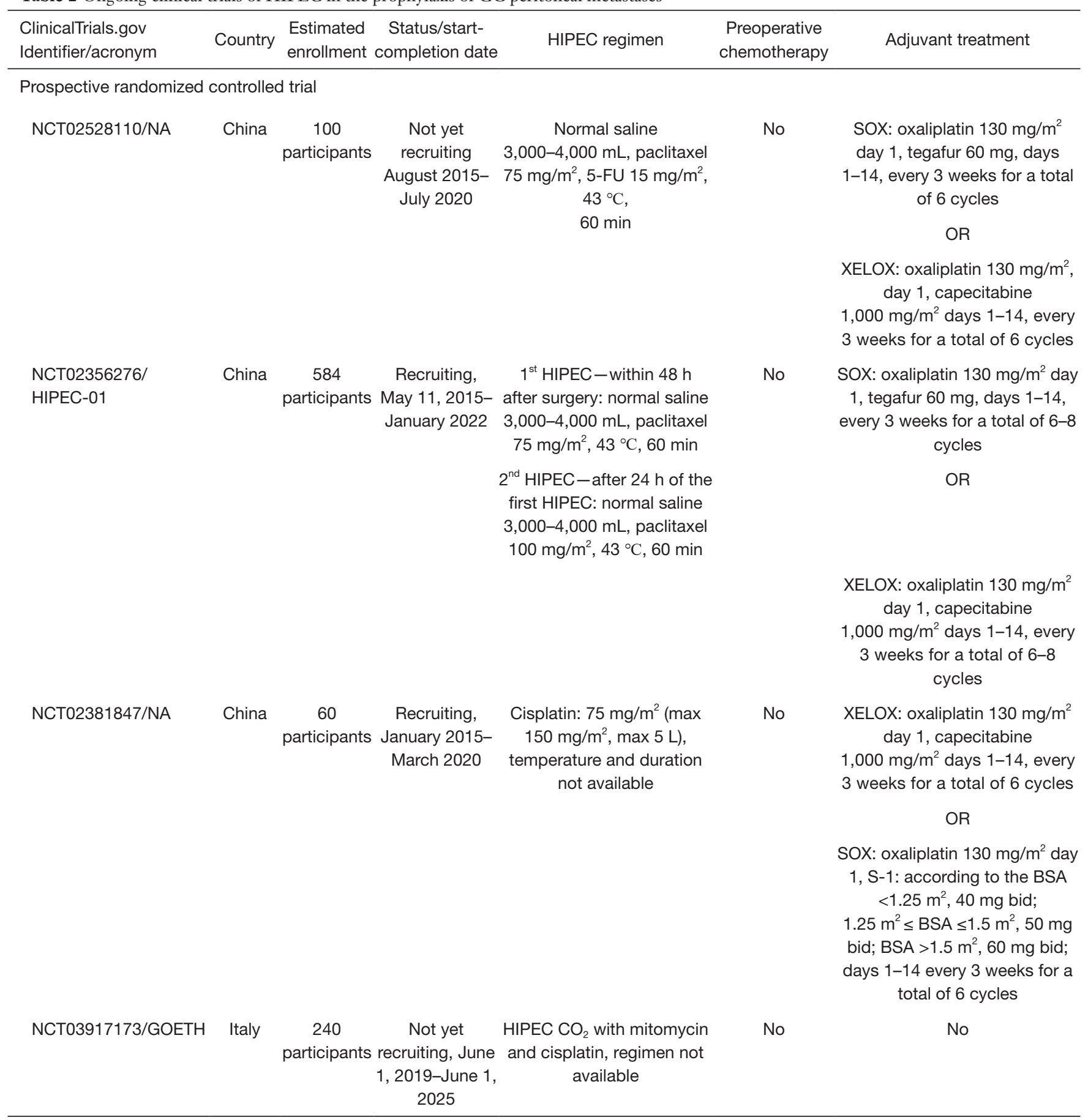

Table 2 (continued) 
Table 2 (continued)

\begin{tabular}{|c|c|c|c|c|c|c|}
\hline $\begin{array}{l}\text { ClinicalTrials.gov } \\
\text { Identifier/acronym }\end{array}$ & Country & $\begin{array}{l}\text { Estimated } \\
\text { enrollment }\end{array}$ & $\begin{array}{l}\text { Status/start- } \\
\text { completion date }\end{array}$ & HIPEC regimen & $\begin{array}{l}\text { Preoperative } \\
\text { chemotherapy }\end{array}$ & Adjuvant treatment \\
\hline NCT02396498/NA & China & $\begin{array}{c}270 \\
\text { participants }\end{array}$ & $\begin{array}{l}\text { Unknown, } \\
\text { April 2014- } \\
\text { December } \\
2016\end{array}$ & $\begin{array}{c}\text { HIPEC }- \text { day } 1 \text { and day } 3 \text { : } \\
\text { normal saline } \\
\text { 2,000-5,000 mL, cisplatin: } \\
60 \mathrm{mg} / \mathrm{m}^{2}, 43^{\circ} \mathrm{C}, 60 \mathrm{~min} ; \\
\text { every } 3 \text { weeks, } 8 \text { cycles; } \\
\text { S-1: } 40-60 \mathrm{mg} / \mathrm{m}^{2} \text { bid, days } \\
1-14, \text { every } 3 \text { weeks, } 8 \\
\text { cycles }\end{array}$ & s. & $\begin{array}{c}\text { Cisplatin: } 60 \mathrm{mg} / \mathrm{m}^{2} \text {, day } 1 \\
\text { intravenous infusion, every } \\
3 \text { weeks; } \mathrm{S}-1: 40-60 \mathrm{mg} / \mathrm{m}^{2} \text {, } \\
\text { days } 1-14, \text { every } 3 \text { weeks; } 8 \\
\text { cycles }\end{array}$ \\
\hline NCT02240524/HIPEC & China & $\begin{array}{c}582 \\
\text { participants }\end{array}$ & $\begin{array}{l}\text { Unknown, July } \\
\text { 2014-July } \\
2019\end{array}$ & $\begin{array}{c}\text { Intraoperative and } \\
\text { postoperative (within } \\
48 \mathrm{~h} \text { after surgery) HIPEC: } \\
\text { normal saline } \\
3,000-4,000 \mathrm{~mL} \text {, paclitaxel } \\
75 \mathrm{mg} / \mathrm{m}^{2}, 43^{\circ} \mathrm{C}, 60 \mathrm{~min}\end{array}$ & No & $\begin{array}{c}\text { XELOX: oxaliplatin } 130 \mathrm{mg} / \mathrm{m}^{2} \\
\text { day } 1 \text {, capecitabine } \\
1,000 \mathrm{mg} / \mathrm{m}^{2} \text { days } 1-14, \text { every } \\
3 \text { weeks for a total of } 8 \text { cycles }\end{array}$ \\
\hline & & & $\begin{array}{c}\text { December } \\
2019\end{array}$ & $\begin{array}{l}2^{\text {nd }} \text { HIPEC }- \text { after } 24 \mathrm{~h} \text { of } \\
\text { the } 1^{\text {st }} \text { HIPEC: normal saline } \\
3,000-4,000 \mathrm{~mL} \text {, paclitaxel } \\
100 \mathrm{mg} / \mathrm{m}^{2}, 43^{\circ} \mathrm{C}, 60 \mathrm{~min}\end{array}$ & $\begin{array}{l}1+\text { oxaliplatin } \\
85 \mathrm{mg} / \mathrm{m}^{2} \text { day } \\
2+\text { fluorouracil } \\
400 \mathrm{mg} / \mathrm{m}^{2} \text { bolus } \\
\text { iv followed by } \\
600 \mathrm{mg} / \mathrm{m}^{2} \\
22 \mathrm{~h} \text { infusion } \\
\text { day } 2 / 3+ \\
\text { leucovorin } \\
200 \mathrm{mg} / \mathrm{m}^{2} \text {, day } \\
2 / 3 \text {; repeated } \\
\text { every } 14 \text { days }\end{array}$ & $\begin{array}{l}\text { OR } \\
\text { SOX: oxaliplatin } 130 \mathrm{mg} / \mathrm{m}^{2} \text { day } \\
\text { 1, S-1: according to the BSA } \\
<1.25 \mathrm{~m}^{2}, 40 \mathrm{mg} \text { bid; } \\
1.25 \mathrm{~m}^{2} \leq \mathrm{BSA} \leq 1.5 \mathrm{~m}^{2}, 50 \mathrm{mg} \\
\text { bid; BSA }>1.5 \mathrm{~m}^{2}, 60 \mathrm{mg} \text { bid; } \\
\text { days } 1-14 \text { every } 3 \text { weeks for a } \\
\text { total of } 6-8 \text { cycles }\end{array}$ \\
\hline
\end{tabular}

HIPEC, hyperthermic intraperitoneal chemotherapy; GC, gastric cancer; BSA, body surface area; NA, not available; 5-FU, 5-fluorouracil; mDOF, docetaxel, oxaliplatin, fluorouracil.

sclerosis (42).

\section{Statistical analysis}

\section{End points}

OS was measured from the date of the operation to the date of death from any cause. Cancer-specific survival (CSS) was measured from the date of the operation to the date of death from GC. Progression-free survival (PFS) was measured from the date of the operation to the date of GC progression. Metastases-free survival was calculated from the date of diagnosis to the first event (distant metastases or death from any cause). All cancer recurrences and deaths were accounted for as events. The two groups were compared using chi-square test for categorical data. Logrank test was used to compare respective survival curves. 
Table 3 Ongoing clinical trials of intraperitoneal chemotherapy in the prophylaxis of GC peritoneal metastases

\begin{tabular}{|c|c|c|c|c|c|}
\hline $\begin{array}{l}\text { ClinicalTrials.gov } \\
\text { Identifier }\end{array}$ & Country & $\begin{array}{l}\text { Estimated } \\
\text { enrollment }\end{array}$ & $\begin{array}{l}\text { Status/start- } \\
\text { completion date }\end{array}$ & IP chemotherapy regimen & $\begin{array}{l}\text { Adjuvant systemic } \\
\text { chemotherapy }\end{array}$ \\
\hline \multicolumn{6}{|c|}{ Prospective randomized controlled trial } \\
\hline & & & & $\begin{array}{l}1-4 \text { postoperative day: } 0.9 \% \\
\text { saline solution } 1 \mathrm{~L} \text { plus } 5-\mathrm{FU} \\
700 \mathrm{mg} / \mathrm{m}^{2} \text { plus sodium } \\
\text { bicarbonate } 50 \mathrm{mEq}\end{array}$ & \\
\hline NCT02269904 & China & 120 participants & $\begin{array}{l}\text { Unknown, April } \\
\text { 2014-June } 2018\end{array}$ & $\begin{array}{l}\text { Fluorouracil implants } 800 \mathrm{mg} \text {, } \\
\text { implanted in the abdominal } \\
\text { cavity during operation }\end{array}$ & $\begin{array}{l}\text { XELOX: oxaliplatin } 130 \mathrm{mg} / \mathrm{m}^{2} \\
\text { day } 1, \text { capecitabine } \\
1,000 \mathrm{mg} / \mathrm{m}^{2} \text { days } 1-14 \text {, every } \\
3 \text { weeks for a total of } 6 \text { cycles }\end{array}$ \\
\hline
\end{tabular}

EPIC, early postoperative intraperitoneal chemotherapy; 5-FU, 5-fluorouracil; GC, gastric cancer; IP, intraperitoneal.

Table 4 Patient characteristics

\begin{tabular}{lccc}
\hline Variable & $\begin{array}{c}\text { Control group }(\mathrm{n}=55), \\
\mathrm{n}(\%)\end{array}$ & $\begin{array}{c}\text { HIPEC group } \\
(\mathrm{n}=68), \mathrm{n}(\%)\end{array}$ & P value \\
\hline $\begin{array}{l}\text { Age (years), } \\
\text { mean } \pm \mathrm{SD}\end{array}$ & $56 \pm 10$ & $56 \pm 8$ & 0.932 \\
Gender & & & 0.408 \\
Male & $18(32.7)$ & $26(38.2)$ & \\
Female & $37(67.3)$ & $42(61.8)$ & \\
pT & & & 0.628 \\
pT4a & $48(87.3)$ & $55(80.9)$ & \\
pT4b & $7(12.7)$ & $13(19.1)$ & \\
pN & & & 0.455 \\
pN0 & $14(25.5)$ & $23(33.8)$ & \\
pN1 & $6(10.9)$ & $8(11.8)$ & \\
pN2 & $14(25.5)$ & $15(22.1)$ & \\
pN3 & $21(38.2)$ & $22(32.4)$ & \\
G & & & \\
Gl & $4(7.3)$ & $6(8.8)$ & \\
GII & $9(16.4)$ & $17(25)$ & \\
GIII & $29(52.7)$ & $39(57.4)$ & \\
GIV & $13(23.6)$ & $6(8.8)$ & \\
\hline
\end{tabular}

HIPEC, hyperthermic intraperitoneal chemotherapy.
For PFS we fitted multivariate Cox regression to define hazard risk (HR) of the independent variables. Additionally, we calculated cumulative incidence (CI) of MPM, liver and other metastases and used Gray test to compare both of groups. Toxicities were assessed according to the CTCAE version 4.03 .

The two groups were well balanced (Table 4).

The analysis of disease progression and CI in the groups under study demonstrated a statistically significant decrease in the frequency and CI of MPM in the HIPEC group as compared with the control group (Table 5), and a concurrent increase in the frequency and $\mathrm{CI}$ of liver-located metastases (in the HIPEC group) and in a conformable frequency and $\mathrm{CI}$ of distant metastases of other locations in both of the groups (Tables 5,6).

The application of HIPEC-based therapy allowed achieving statistically significant survival improvements (Table 7).

Our multivariate analysis using the Cox model showed an increased risk of disease progression: (I) in cases of regional lymph node metastases; (II) in the control group (i.e., in the absence of adjuvant HIPEC) (Table 8).

As mentioned earlier, our HIPEC regimen employed cisplatin in conjunction with doxorubicin as one of the 
Table 5 Patients with disease progression after surgery alone and HIPEC plus surgery

\begin{tabular}{|c|c|c|c|}
\hline Characteristics of disease progression & Group & $\mathrm{N}(\%)$ & $P$ value \\
\hline Progression (with peritoneal dissemination) & HIPEC & $37(54.4)$ & \\
\hline \multirow[t]{2}{*}{ Metachronous peritoneal metastases* } & Control & $40(72.7)$ & $<0.001$ \\
\hline & HIPEC & $16(23.5)$ & \\
\hline \multirow[t]{2}{*}{ Liver metastases $^{\star \star}$} & Control & $3(5.5)$ & 0.018 \\
\hline & HIPEC & $14(20.6)$ & \\
\hline \multirow[t]{2}{*}{ Other metastases ${ }^{\star \star \star}$} & Control & $2(3.6)$ & 0.186 \\
\hline & HIPEC & $7(10.3)$ & \\
\hline
\end{tabular}

*, counting in patients with MPM and even with other distant metastases; ${ }^{* *}$, counting in patients with metastases in the liver and other organs except for the peritoneum; ${ }^{* \star *}$, counting in patients with metastases in organs other than the peritoneum and the liver. HIPEC, hyperthermic intraperitoneal chemotherapy; MPM, metachronous peritoneal metastases.

Table 6 Cumulative incidence (CI) of GC progression events

\begin{tabular}{llll}
\hline Cumulative incidence & Control group, Cl \pm SE & HIPEC group, Cl \pm SE & P value (Gray's test) \\
\hline Metachronous peritoneal metastases & $72.8 \pm 6.4$ & $24.0 \pm 5.5$ & $<0.001$ \\
Liver metastases & $3.6 \pm 2.6$ & $19.3 \pm 5.1$ & 0.015 \\
Other metastases & $4.0 \pm 2.9$ & $9.6 \pm 3.8$ & 0.137 \\
\hline
\end{tabular}

GC, gastric cancer; SE, standard error.

Table 7 Four-year survival probability $(\% \pm \mathrm{SE})$ in HIPEC and control groups

\begin{tabular}{llll}
\hline Survival & Control group & HIPEC group & $P_{\text {log-rank }}$ \\
\hline Overall survival & $34.6 \pm 6.6$ & $47.1 \pm 6.1$ & 0.2 \\
Cancer-specific survival & $36.7 \pm 6.9$ & $51.8 \pm 6.3$ & 0.09 \\
Progression-free survival & $19.6 \pm 5.6$ & $47.1 \pm 6.3$ & $<0.001$ \\
Dissemination-free survival & $22.7 \pm 6.0$ & $51.9 \pm 6.3$ & $<0.001$ \\
Metastases-free survival & $31.1 \pm 6.5$ & $42.6 \pm 6.0$ & 0.2 \\
\hline
\end{tabular}

HIPEC, hyperthermic intraperitoneal chemotherapy; SE, standard error.

most widely used combinations in previously run trials. Given the high frequency of complications associated with cisplatin, its dosage was reduced to $50 \mathrm{mg} / \mathrm{m}^{2}$, well below its dosage in earlier reported trials. For example, Farma et al. (40) observed hematological toxicity in $27.8 \%$ of patients and impairment of the renal function in $16.7 \%$ of patients after using cisplatin in doses of $150-300 \mathrm{mg} / \mathrm{m}^{2}$. Kusamura et al. (47) showed that the application of cisplatin at $240 \mathrm{mg} / \mathrm{m}^{2}$ resulted in a high risk of grade III-
IV complications (according to the WHO criteria). As regards doxorubicin, our choice of this drug to supplement cisplatin was prompted by its previously reported high cytostatic efficacy in GC treatment and its relatively lowlevel toxicity $(21,22,33,42,46)$. For example, in a study on doxorubicin dose escalation undertaken by Sugarbaker $(42,48)$ it was reported that a low total dose of $15 \mathrm{mg} / \mathrm{m}^{2}$ of intraperitoneal doxorubicin resulted in forming a thin layering of fibrous tissue on peritoneal surfaces that was 
Table 8 Factors associated with GC progression (Cox model)

\begin{tabular}{llll}
\hline Variables & $\beta$ & HR (95\% confidence intervals HR) & P value \\
\hline pN1-2 vs. pN0 & 0.86 & $2.4(1.2-4.5)$ & 0.009 \\
pN3 vs. pN0 & 1.60 & $4.9(2.6-9.4)$ & $<0.001$ \\
Surgery vs. surgery + HIPEC & 0.71 & $2.0(1.3-3.2)$ & 0.002 \\
\hline
\end{tabular}

GC, gastric cancer; HR, hazard ratio; HIPEC, hyperthermic intraperitoneal chemotherapy.

not observed to interfere with subsequent gastrointestinal function. Based on this and other referenced reports about doxorubicin low-level toxicity, the dosage of doxorubicin in our study was raised to $50 \mathrm{mg} / \mathrm{m}^{2}$ in a $5 \mathrm{~L}$ perfusate to add to the cancer-killing effect of cisplatin whose dosage was lowered in view of its comparatively high toxicity. Such a dosage combination of the two drugs (cisplatin $50 \mathrm{mg} / \mathrm{m}^{2}$ plus doxorubicin $50 \mathrm{mg} / \mathrm{m}^{2}$ ) proved to be effective in terms of attaining a good prophylactic effect and an adequate tolerability of the proposed HIPEC regimen. In essence, there weren't any cases of clinical manifestations of peritoneal adhesions during the follow-up patient monitoring or any pronounced adhesion processes or intestinal fibrosis when performing second-look laparoscopy. All registered complications in the patients of both groups are presented in Table 9.

\section{Combining HIPEC with adjuvant SCT}

The reviewed literary sources and our own findings confirm the necessity and practicability of adjuvant HIPEC modality to prevent GC progression after performing radical surgery and also underscore the need for a follow-up adjuvant SCT to prevent GC systemic progression including liver metastasizing, the second most frequent GC relapse after MPM. In effect, in our report we called attention to the post-HIPEC greater risk of developing distant lymphohematogenous metastases after HIPEC [relative risk (RR) 7.5 (2.2-25), $\mathrm{P}=0.001]$ (2).

As was noted earlier in this review, unlike trials in the past, most of current studies on prophylactic HIPEC efficacy include follow-up adjuvant and/or perioperative SCT (Tables 2,3). Employment of the modes of intravenous and intraperitoneal delivery of chemotherapy drugs allows avoiding chemical incompatibility with drugs administered intraperitoneally, and produces a double impact on peritoneal metastases from both subperitoneal vessels and the abdominal cavity. According to published data on HIPEC plus SCT modality, there are three SCT delivery methods: (I) postoperatively (49,50), (II) intraoperatively as in the GASTRICHIP multicenter study (51), and (III) perioperatively (52).

There are too few studies on the HIPEC plus SCT multimodal approach (49-53) and none on benefits to be gained from repeated HIPEC administration. This fact brings into focus the pressing need of stepping up efforts in these fields of research. In the meantime, our small-scale study of 19 patients who underwent a combined surgery plus HIPEC plus SCT treatment showed a dramatic improvement in the metastases-free 3-year survival rate to up to $91.0 \% \pm 9.0 \%\left(\mathrm{P}_{\text {log-rank }}=0.025\right)$ compared with $48.6 \% \pm 6.4 \%$ for patients who underwent only a combined surgery plus HIPEC (54).

Viewed overall, these data are indicative of ongoing intense efforts of searching for optimal strategies of employing adjuvant HIPEC in GC management covering all its aspects from administration techniques, chemotherapy agents and the practicability of supplementing it with adjuvant chemotherapy. At this point in time no definitive conclusion about the most effective HIPEC strategy can be drawn until further prospective randomized studies are performed.

\section{Conclusions regarding current recommendations for treatment}

In summary, the analyzed published research data and the results of our own study give grounds to state that the administration of prophylactic HIPEC to radically operated patients with advanced GC is a totally justifiable and a practical treatment modality from the point of view of cancer therapy outcomes. No less important is the fact that the administration of this multimodal treatment is comparable with surgery alone in terms of morbidity and mortality. For all that, there are still a host of questions that wait to be answered:

(I) Most of the studies published to date originate from Eastern Pacific countries except for some 
Table 9 Postoperative morbidity in HIPEC and control groups

\begin{tabular}{|c|c|c|}
\hline Type of complications & Grade CTCAE v. 4.03 & $\mathrm{~N}(\%)$ \\
\hline \multicolumn{3}{|l|}{ Non-surgical complications } \\
\hline Enterocolitis & I & $1(5.0)$ \\
\hline Fever of unclear genesis & I & $2(10.0)$ \\
\hline Pleural effusion & II & $1(5.0)$ \\
\hline Thrombophlebitis of subcutaneous veins & II & $1(5.0)$ \\
\hline Acute kidney failure & II & $1(5.0)$ \\
\hline \multicolumn{3}{|l|}{ Surgical complications } \\
\hline Volvulus of ileal loops, serosal peritonitis & IV & $1(5.0)$ \\
\hline Mesothrombosis & V & $1(5.0)$ \\
\hline Esophagojejunal anastomotic leak & V & $2(10.0)$ \\
\hline Total & & 20 \\
\hline \multicolumn{3}{|l|}{ Control group } \\
\hline \multicolumn{3}{|l|}{ Non-surgical complications } \\
\hline Pneumonia & $\|$ & $4(33.3)$ \\
\hline Myocardial infarction & ॥ & $1(8.3)$ \\
\hline Left liver lobe necrosis, paralytic intestinal obstruction & IV & $1(8.3)$ \\
\hline Total & & 12 \\
\hline
\end{tabular}

HIPEC, hyperthermic intraperitoneal chemotherapy.

studies elsewhere based on small cohorts of patients $(2,55,56)$. It raises a question about the applicability of the obtained results to the European and American populations. Hence, there is a need for expanding geographical frontiers of HIPEC studies. Promising in this respect is the GASTRICHIP project that could hopefully answer this question with regard to the European population upon its completion.
(II) The number of randomized studies on adjuvant HIPEC are still insufficient for a subgroup assessment of efficacy of given chemotherapy regimens and generation of evidence-based recommendations on the individual use of chemotherapy agents and their combinations, and HIPEC procedural techniques.

(III) Further prospective randomized studies are warranted to assess the need for, and practicability 
of, complementing HIPEC with adjuvant SCTs and to develop definitive recommendations on the use of effective regimens for adjuvant chemotherapy.

\section{Acknowledgments}

The authors wish to express their gratitude to Dr. PH Sugarbaker for his encouragement, thought-provoking comments and help throughout the preparation of this manuscript.

Funding: None.

\section{Footnote}

Provenance and Peer Review: This article was commissioned by the Guest Editors (Paul H. Sugarbaker and Kurt Van der Speeten) for the Focused Issue "Intraperitoneal Chemotherapy for Peritoneal Metastases: HIPEC, EPIC, NIPEC, PIPAC and More" published in fournal of Gastrointestinal Oncology. This article has undergone external peer review.

Conflicts of Interest: All authors have completed the ICMJE uniform disclosure form (available at http://dx.doi. org/10.21037/jgo-20-129). The Focused Issue was sponsored by the Peritoneal Surface Oncology Group International (PSOGI). The authors have no other conflicts of interest to declare.

Ethical Statement: The authors are accountable for all aspects of the work in ensuring that questions related to the accuracy or integrity of any part of the work are appropriately investigated and resolved.

Open Access Statement: This is an Open Access article distributed in accordance with the Creative Commons Attribution-NonCommercial-NoDerivs 4.0 International License (CC BY-NC-ND 4.0), which permits the noncommercial replication and distribution of the article with the strict proviso that no changes or edits are made and the original work is properly cited (including links to both the formal publication through the relevant DOI and the license). See: https://creativecommons.org/licenses/by-nc-nd/4.0/.

\section{References}

1. Ji ZH, Peng KW, Yu Y, et al. Current status and future prospects of clinical trials on CRS + HIPEC for gastric cancer peritoneal metastases. Int J Hyperthermia 2017;33:562-70.

2. Reutovich MYu, Krasko OV, Sukonko OG. Hyperthermic intraperitoneal chemotherapy in serosa-invasive gastric cancer patients. Eur J Surg Oncol 2019;45:2405-11.

3. Thomassen I, van Gestel YR, van Ramshorst B, et al. Peritoneal carcinomatosis of gastric origin: a populationbased study on incidence, survival and risk factors. Int J Cancer 2014;134:622-8.

4. Yu CC, Levinson DA, Dunn JA, et al. Pathological prognostic factors in the second British Stomach Cancer Group trial of adjuvant therapy in resectable gastric cancer. Br J Cancer 1995; 71:1106-10.

5. Marutsuka T, Shimada S, Shiomori K, et al. Mechanisms of peritoneal metastasis after operation for non-serosa invasive gastric carcinoma: an ultrarapid detection system for intraperitoneal free cancer cells and a prophylactic strategy for peritoneal metastasis. Clin Cancer Res 2003;9:678-85.

6. Takebayashi K, Murata S, Yamamoto H, et al. Surgeryinduced peritoneal cancer cells in patients who have undergone curative gastrectomy for gastric cancer. Ann Surg Oncol 2014;21:1991-7.

7. Al-Batran SE, Hofheinz RD, Pauligk C, et al. Histopathological regression after neoadjuvant docetaxel, oxaliplatin, fluorouracil, and leucovorin versus epirubicin, cisplatin, and fluorouracil or capecitabine in patients with resectable gastric or gastro-oesophageal junction adenocarcinoma (FLOT4-AIO): results from the phase 2 part of a multicentre, open-label, randomized phase 2/3 trial. Randomized controlled trial. Lancet Oncol 2016;17:1697-708.

8. Macdonald JS, Smalley SR, Benedetti J, et al. Chemoradiotherapy after surgery compared with surgery alone for adenocarcinoma of the stomach or gastroesophageal junction. N Engl J Med 2001;345:725-30.

9. Kuramoto M, Shimada S, Ikeshima S, et al. Extensive intraoperative peritoneal lavage as a standard prophylactic strategy for peritoneal recurrence in patients with gastric carcinoma. Ann Surg 2009;250:242-6.

10. Lybaert W, Dero I, Peeters M, et al. Highlights of the gastrointestinal cancers symposium 2018. Belg J Med Oncol 2018;12:133-41.

11. Yan TD, Black D, Sugarbaker PH, et al. A systematic review and meta-analysis of the randomized controlled trials on adjuvant Intraperitoneal chemotherapy for resectable gastric cancer. Ann Surg Oncol 2007;14:2702-13.

12. Huang JY, Xu YY, Sun Z, et al. Comparison different 
methods of intraoperative and intraperitoneal chemotherapy for patients with gastric cancer: a metaanalysis. Asian Pac J Cancer Prev 2012;13:4379-85.

13. Di Vita M, Cappellani A, Piccolo G, et al. The role of HIPEC in the treatment of peritoneal carcinomatosis from gastric cancer: between lights and shadows. Anticancer Drugs 2015;26:123-38.

14. Brücher BL, Piso P, Verwaal V, et al. Peritoneal carcinomatosis: cytoreductive surgery and HIPECoverview and basics. Cancer Invest 2012;30:209-24.

15. Yu W, Whang I, Chung HY, et al. Indications for early postoperative intraperitoneal chemotherapy of advanced gastric cancer: results of a prospective randomized trial. World J Surg 2001;25:985-90.

16. Sugarbaker PH. Laboratory and clinical basis for hyperthermia as a component of intracavitary chemotherapy. Int J Hyperthermia 2007;23:431-42.

17. Mohamed F, Marchettini P, Stuart OA, et al. Thermal enhancement of new chemotherapeutic agents at moderate hyperthermia. Ann Surg Oncol 2003;10:463-8.

18. Hildebrandt B, Wust P, Ahlers O, et al. The cellular and molecular basis of hyperthermia. Crit Rev Oncol Hematol 2002;43:33-56.

19. Eppink B, Krawczyk PM, Stap J, et al. Hyperthermiainduced DNA repair deficiency suggests novel therapeutic anti-cancer strategies. Int J Hyperthermia 2012;28:509-17.

20. Coccolini F, Cotte E, Glehen O, et al. Intraperitoneal chemotherapy in advanced gastric cancer. Meta-analysis of randomized trials. Eur J Surg Oncol 2014;40:12-26.

21. Mi DH, Li Z, Yang KH, et al. Surgery combined with intraoperative hyperthermic intraperitoneal chemotherapy (IHIC) for gastric cancer: a systematic review and meta-analysis of randomised controlled trials. Int J Hyperthermia 2013;29:156-67.

22. Feingold PL, Kwong ML, Davis JL, et al. Adjuvant intraperitoneal chemotherapy for the treatment of gastric cancer at risk for peritoneal carcinomatosis: a systematic review. J Surg Oncol 2017;115:192-201.

23. Koga S, Hamazoe R, Maeta M, et al. Prophylactic therapy for peritoneal recurrence of gastric cancer by continuous hyperthermic peritoneal perfusion with mitomycin C. Cancer 1988;61:232-7.

24. Hamazoe R, Maeta M, Kaibara N. Intraperitoneal thermochemotherapy for prevention of peritoneal recurrence of gastric cancer. Final results of a randomized controlled study. Cancer 1994;73:2048-52.

25. Ikeguchi M, Kondou A, Oka A, et al. Effects of continuous hyperthermic peritoneal perfusion on prognosis of gastric cancer with serosal invasion. Eur J Surg 1995;161:581-6.

26. Fujimoto S, Takahashi M, Mutou T, et al. Successful intraperitoneal hyperthermic chemoperfusion for the prevention of postoperative peritoneal recurrence in patients with advanced gastric carcinoma. Cancer 1999;85:529-34.

27. Yonemura Y, de Aretxabala X, Fujimura T, et al. Intraoperative chemohyperthermic peritoneal perfusion as an adjuvant to gastric cancer: final results of a randomized controlled study. Hepatogastroenterology 2001;48:1776-82.

28. Seshadri RA, Glehen O. Cytoreductive surgery and hyperthermic intraperitoneal chemotherapy in gastric cancer. World J Gastroenterol 2016;22:1114-30.

29. Kim JY, Bae HS. A controlled clinical study of serosainvasive gastric carcinoma patients who underwent surgery plus intraperitoneal hyperthermo-chemo-perfusion (IHCP). Gastric Cancer 2001;4:27-33.

30. Kunisaki C, Shimada H, Nomura M, et al. Lack of efficacy of prophylactic continuous hyperthermic peritoneal perfusion on subsequent peritoneal recurrence and survival in patients with advanced gastric cáncer. Surgery 2002;131:521-8.

31. Songun I, Putter H, Kranenbarg EM, et al. Surgical treatment of gastric cancer: 15 -year follow-up results of the randomised nation-wide Dutch D1 D2 trial. Lancet Oncol 2010;11:439-49.

32. Bickenbach K, Strong VE. Comparisons of Gastric Cancer Treatments: East vs. West. J Gastric Cancer 2012;12:5562. Erratum in: J Gastric Cancer 2012;12:262.

33. Sautner T, Hofbauer F, Depisch D, et al. Adjuvant intraperitoneal cisplatin chemotherapy does not improve long-term survival after surgery for advanced gastric cancer. J Clin Oncol 1994;12:970-4.

34. Fushida S, Oyama K, Kinoshita J, et al. Intraperitoneal chemotherapy as a multimodal treatment for gastric cancer patients with peritoneal metastasis. J Cancer Ther 2013;4:6-15.

35. Tentes AA, Spiliotis ID, Korakianitis OS, et al. Adjuvant perioperative intraperitoneal chemotherapy in locally advanced colorectal carcinoma: Preliminary results. ISRN Surg 2011;2011:529876.

36. Ortega-Deballon P, Facy O, Jambet S, et al. Which method to deliver hyperthermic intraperitoneal chemotherapy with oxaliplatin? An experimental comparison of open and closed techniques. Ann Surg Oncol 2010;17:1957-63.

37. Facy O, Combier C, Poussier M, et al. High pressure does not counterbalance the advantages of open techniques over closed techniques during heated intraperitoneal 
chemotherapy with oxaliplatin. Surgery 2015;157:72-8.

38. Benoit L, Cheynel N, Ortega-Deballon P, et al. Closed hyperthermic intraperitoneal chemotherapy with open abdomen: a novel technique to reduce exposure of the surgical team to chemotherapy drugs. Ann Surg Oncol 2008;15:542-6.

39. Miyashiro I, Furukawa H, Sasako M, et al. Randomized clinical trial of adjuvant chemotherapy with intraperitoneal and intravenous cisplatin followed by oral fluorouracil (UFT) in serosa-positive gastric cancer versus curative resection alone: Final results of the Japan Clinical Oncology Group trial JCOG9206-2. Gastric Cancer 2011;14:212-8.

40. Farma JM, Pingpank JF, Libutti SK, et al. Limited survival in patients with carcinomatosis from foregut malignancies after cytoreduction and continuous hyperthermic peritoneal perfusion. J Gastrointest Surg 2005;9:1346-53.

41. Furman MJ, Picotte RJ, Wante MJ, et al. Higher flow rates improve heating during hyperthermic intraperitoneal chemoperfusion. J Surg Oncol 2014;110:970-5.

42. Sugarbaker PH, Mora JT, Carmignani P, et al. Update on chemotherapeutic agents utilized for perioperative intraperitoneal chemotherapy. Oncologist 2005;10:112-22.

43. Glehen O, Mohamed F, Gilly FN. Peritoneal carcinomatosis from digestive tract cancer: new management by cytoreductive surgery and intraperitoneal chemohyperthermia. Lancet Oncol 2004;5:219-28.

44. Fugazzola P, Coccolini F, Montori G, et al. Overall and disease-free survival in patients treated with CRS + HIPEC with cisplatin and paclitaxel for gastric cancer with peritoneal carcinomatosis. J Gastrointest Oncol 2017;8:572-82.

45. Goodman MD, McPartland S, Detelich D, et al. Chemotherapy for intraperitoneal use: a review of hyperthermic intraperitoneal chemotherapy and early postoperative intraperitoneal chemotherapy. J Gastrointest Oncol 2016;7:45-57.

46. Stephens AD, Belliveau J, Sugarbaker PH. Intraoperative hyperthermic lavage with cisplatin for peritoneal carcinomatosis and sarcomatosis. In: Sugarbaker PH. editor. Peritoneal Carcinomatosis: Drugs and Diseases. Boston: Kluwer, 1996:15-30.

47. Kusamura S, Younan R, Baratti D, et al. Cytoreductive surgery followed by intraperitoneal hyperthermic perfusion: analysis of morbidity and mortality in 209 peritoneal surface malignancies treated with closed abdomen technique. Cancer 2006;106:1144-53.
48. Sugarbaker PH. Early postoperative intraperitoneal adriamycin as an adjuvant treatment for visceral and retroperitoneal sarcoma. In: Sugarbaker PH. editor. Peritoneal Carcinomatosis: Drugs and Diseases. Boston: Kluwer, 1996:7-14.

49. Zuo Y, Xu M, Shen D, et al. Postoperative intraperitoneal hyperthermic chemoperfusion combined with intravenous chemotherapy for 82 advanced gastric cancer patients. Zhonghua Zhong Liu Za Zhi 2004;26:247-9.

50. Shi C, Yang B, Chen Q, et al. Retrospective analysis of adjuvant intraperitoneal chemotherapy effect prognosis of resectable gastric cancer. Oncology 2011;80:289-95.

51. Glehen O, Passot G, Villeneuve L, et al. GASTRICHIP: $\mathrm{D} 2$ resection and hyperthermic intraperitoneal chemotherapy in locally advanced gastric carcinoma: a randomized and multicenter phase III study. BMC Cancer 2014;14:183.

52. Costa WL Jr, Coimbra FJ, Ribeiro HS, et al. Safety and preliminary results of perioperative chemotherapy and hyperthermic intraperitoneal chemotherapy (HIPEC) for high-risk gastric cancer patients. World J Surg Oncol 2012;10:195.

53. Xue SL, Su HF, Hu XQ, et al. Adjuvant combined systemic chemotherapy and intraperitoneal chemotherapy for locally advanced gastric cancer. Oncol Lett 2012;4:1309-14.

54. Reutovich MYu, Krasko OV, Sukonko OG. Efficacy of Adjuvant Systemic Chemotherapy Combined with Radical Surgery and Hyperthermic Intraperitoneal Chemotherapy in Gastric Cancer Treatment. Indian J Surg Oncol 2020;11:337-43.

55. Scaringi S, Kianmanesh R, Sabate JM, et al. Advanced gastric cancer with or without peritoneal carcinomatosis treated with hyperthermic intraperitoneal chemotherapy: a single western center experience. Eur J Surg Oncol 2008;34:1246-52.

56. Coccolini F, Celotti A, Ceresoli M, et al. Hyperthermic intraperitoneal chemotherapy (HIPEC) and neoadjuvant chemotherapy as prophylaxis of peritoneal carcinosis from advanced gastric cancer-effects on overall and disease free survival. J Gastrointest Oncol 2016;7:523-9.

Cite this article as: Reutovich MY, Krasko OV, Sukonko OG. Hyperthermic intraperitoneal chemotherapy in prevention of gastric cancer metachronous peritoneal metastases: a systematic review. J Gastrointest Oncol 2021;12(Suppl 1):S5-S17. doi: 10.21037/jgo-20-129 